\title{
Управление инновациями
}

УдК: 330.322.16

КУЗНЕЦОВА МАРГАРИТА ВААДИМИРОВНА

к.ф.н, доцент, доцент кафедры экономики и финансов ФГБОУ ВО

«Магнитогорский государственный технический университет им. Г.И. Носова»,

e-mail:wj27@mail.ru

\section{СОВЕРШЕНСТВОВАНИЕ ИННОВАЦИОННОЙ ИНФРАСТРУКТУРЫ НА РЕГИОНААЬНОМ УРОВНЕ}

\begin{abstract}
Аннотауия. Цель работы. В статье приводится модель «инновачионного лифта» регионального уровня на примере Челябинской области. Метод и методология проведения работы. Проведен статистический анализ объемов инвестиций в инновационные проекты на разных стадиях в рамках федеральных округов. Результаты. Выявлена крайняя степень не-

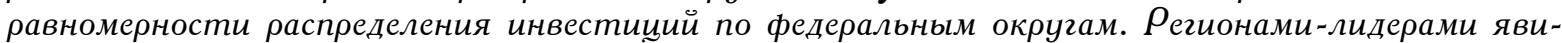
лись Центральный федеральный округ, Северо-Западный и Сибирский. Это обусловлено, в т. ч., тем, что в этих территориях наиболее развита инновационная инфраструктура. Вместе с тем механизм поддержки инновационных проектов через государственные институты, названный «инновационным лифтом», не смог себя реализовать в силу обтективных причин, выделенных автором. Предлагается внедрить на региональном уровне предложенную модель «инновационного лифта», который должен способствовать более быстрому становлению инновационного предпринимательства в регионах. Область применения результатов.

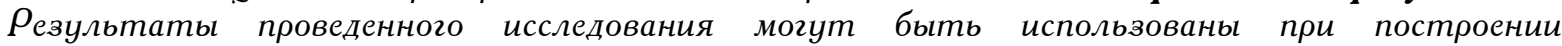

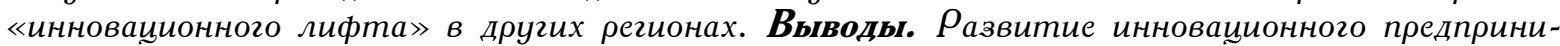
мательства невозможно без наличия соответствующей инфраструктуры. Существующие методы поддержки инновационных проектов работают недостаточно эффективно. Для активизации формирования и развития инновационных проектов необходимо использовать модернизированную модель «инновационного лифта».
\end{abstract}

Ключевые слова: инновачионный проект, инновачионная инфраструктура, инновационный лифт.

KUZNETSOVA MARGARET VLADIMIROVNA

Ph. D., associate Professor, associate Professor of the Department of Economics and Finance "Magnitogorsk state technical University named after G. I. Nosov", e-mail:wj27@mail.ru

\section{THE IMPROVEMENT OF INNOVATIVE INFRASTRUCTURE AT REGIONAL LEVEL}

Abstract. Purpose of work. The article presents a model of "innovative Elevator" at the regional level on the example of the Chelyabinsk region. Method and methodology of the work. A statistical analysis of the volume of investment in innovative projects at different stages within the Federal districts was carried out. Results. The extreme degree of unevenness in the distribution of investments across Federal districts is revealed. The leading regions were the Central Federal district, NorthWestern and Siberian regions. This is due, inter alia, to the fact that these territories have the most developed innovative infrastructure. However, the mechanism for supporting innovative projects through state institutions, called the "innovation Elevator", could not be implemented due to objective reasons identified by the author. It is proposed to implement the proposed model of "innovation Elevator" at the regional level, which should contribute to the faster development of innovative entrepreneurship in the regions. Scope of the results. The results of the research can be used in the construction of an "innovative Elevator" in other regions. Conclusions. The development of innovative entre-

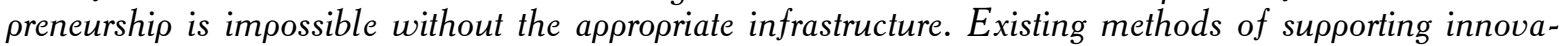
tive projects do not work effectively enough. To activate the formation and development of innovative projects, it is necessary to use a modernized model of the "innovation Elevator".

Keywords: innovative project, innovative infrastructure, innovative Elevator. 
Введение. Для осуществления наукоемкого и высокотехнологичного предпринимательства необходимо постоянно развивать инновационную инфраструктуру [10]. Инновационные предприятия на этапе своего формирования сталкиваются с рядом проблем. Трудности могут выражаться в нехватке оборотных средств, отсутствии персонала соответствующего уровня квалификации, недоступности информационной помощи в виде консалтинга, а также настороженном отношении со стороны инвесторов и потенциальных партнеров в силу высокорискованного бизнеса, основанного на внедрении инноваций. Помимо того, инновационные предприятия относятся к наукоемким, а следовательно, к предприятиям с долгим сроком создания прототипа и окупаемости. Однако для успешного развития экономики страны подобные предприятия безусловно необходимы. Следовательно, решение этой проблемы кроется в создание такой инфраструктуры, которая бы смогла интегрировать ресурсы науки, возможности государственных структур, крупных предприятий, а также среднего и малого бизнеса [6].

Методы исследования. Совокупность факторов, институтов, элементов инновационной инфраструктуры, влияющих на появление и ускорение развития инновационных предприятий, можно определить, как «инновационный лифт». Инновационный лифт представляет собой объединение специфических институтов, которые выступают механизмами и задают нужное направление движения инновационной системе. Эти институты-механизмы инновационного прогресса должны выполнять такие функции, как обеспечение финансовой составляющей инновационной деятельности, предоставление консалтинговых услуг, формирование инфраструктуры для формирования и дальнейшего развития инновационного процесса. Инновационный лифт движется не хаотично, а в определенной последовательности - по этажам, которые соответствуют хронологическим этапам развития инновационной фирмы. Первый этаж это стадия посева, второй - старт, далее - ранний рост, последним этажом может быть такая стадия, как расширение. Двигаясь, инновационный лифт тем самым продвигает инновационный проект поочередно от одной стадии к последующей стадии инновационного процесса.

Поскольку каждый этап развития инновационного проекта весьма специфичен и имеет разные цели, поэтому каждая стадия требует специальных инструментов поддержки (табл. 1).

Таблища 1

Направления поддержки инновационных проектов в зависимости от их стадии развития

\begin{tabular}{|l|l|}
\hline Стадия развития инновационного проекта & \multicolumn{1}{|c|}{ Направление поддержки } \\
\hline Посевная & Преобразование инновационной идеи в инновационный проект \\
\hline Начальная (start-up) & Разработка грамотного бизнес-плана, создание опытного образца \\
\hline Ранний рост (early stage) & $\begin{array}{l}\text { Запуск первой очереди производства, выход инновационного продукта } \\
\text { на рынок }\end{array}$ \\
\hline Расширение (expansion) & $\begin{array}{l}\text { Ускорение завоевания большей доли рынка, увеличение объема произ- } \\
\text { водства и реализации }\end{array}$ \\
\hline
\end{tabular}

Инновационный лифт в своей основе имеет такую идею, как ускорение инновационного процесса. Этот механизм за счет соответствующих институтов призван ускорить коммерциализацию новых технологий, ускорить формирование и развитие тех предприятий, которые в своей деятельности опираются на новации [3].

Термин «инновационный лифт» в нашей стране стало применяться в апреле 2010 г. Это было вызвано подписанием соглашения, которое называлось «Соглашением десяти». Цель этого соглашения заключалась в регулировании сотрудничества институтов развития инновационного предпринимательства, созданных и функционирующих на тот момент времени. К членам этой «десятки» относятся ВЭБ, МСП Банк, Роснано, Фонд «Сколково», РВК (Российская венчурная компания). Все эти организации при всех своих возможностях не смогли заставить заработать «подъемное устройство» так, чтобы он смог на достаточном уровне пройти все этажи.

Неработоспособность инновационного лифта оказалась очевидной для всех его участников: «создатель лифта» - правительство, «пассажиры» (инновационные предприниматели), 
«лифтеры» (персонал институтов развития) [2].

Инновационный лифт не способен выполнять свой функционал по ряду факторов:

- во-первых, отсутствует единоличный «хозяин проекта»;

- во-вторых, на формирование подъемной мощности лифта не выделены ресурсы;

- в-третьих, для институтов развития - участников инновационного лифта - не определена ответственность за результаты деятельности по продвижению инновационных проектов;

- в-четвертых, различные институты развития выдвигают различные требования к «пассажирам» лифта. Данный факт обусловлен отсутствием полноценного единоличного управляющего «инновационным лифтом»;

- в-пятых, сами институты развития в силу различия в целях своей деятельности плохо совместимы в рамках достижения единой цели - ускорения развития инновационных проектов;

- в-шестых, инновационный лифт основан преимущественно на государственных организациях, которые бюрократичны сами по своей природе. Для решения задач рыночного типа государственные институты зачастую бывают неэффективны.

Резюмируя, отметим, что инновационный лифт, будучи подконтрольным государству, не может быть эффективным. Организации, от которых зависит качество работы инновационного лифта, должны быть преимущественно частными (минимум на $70 \%$ ). В конечной точке прибытия инновационного лифта должен располагаться покупатель/потребитель инновационного продукта или покупатель инновационной компании. Удовлетворение именно их интересов должно определять работу лифта.

Таким образом, инновационный лифт как организационный механизм инновационного процесса должен работать под руководством единого управляющего органа и при этом обеспечивать потребности как потенциальных инвесторов, так и инноваторов.

Развитие венчурного бизнеса в регионах нашей страны происходит крайне неравномерно. В регионах с более высоким уровнем сформированности венчурной инфраструктуры объемы инвестиций во много раз превышают размеры тех финансовых ресурсов, которые осваиваются в «отсталых» субъектах РФ [5]. Статистические данные о распределении объемов инвестиций по федеральным округам РФ представлены в табл. 2.

Таблица 2

Распределение объемов инвестиций по федеральным округам РФ [4].

\begin{tabular}{|l|c|c|c|c|c|c|c|c|c|c|}
\hline \multirow{2}{*}{ Федеральный округ } & \multicolumn{2}{|c|}{2014} & \multicolumn{2}{|c|}{2015} & \multicolumn{2}{|c|}{2016} & \multicolumn{2}{|c|}{2017} & \multicolumn{2}{c|}{2018} \\
\cline { 2 - 14 } & $\begin{array}{c}\text { млн } \\
\text { долл. }\end{array}$ & $\%$ & $\begin{array}{c}\text { млн } \\
\text { долл. }\end{array}$ & $\%$ & $\begin{array}{c}\text { млн } \\
\text { долл. }\end{array}$ & $\%$ & $\begin{array}{c}\text { млн } \\
\text { долл. }\end{array}$ & $\begin{array}{c}\text { млн } \\
\text { долл. }\end{array}$ & \% \\
\hline Центральный & 552 & 90,3 & 397 & 38,1 & 521 & 63,8 & 882 & 59,3 & 709 & 91,7 \\
\hline Северо-Западный & 19 & 3,1 & 370 & 35,5 & 285 & 34,9 & 298 & 20,0 & 24 & 3,1 \\
\hline Приволжский & 8 & 1,2 & 1 & 0,1 & 7 & 0,9 & 17 & 1,2 & 28 & 3,6 \\
\hline Южный & 0 & 0,0 & 0 & 0,0 & 0 & 0,0 & 5 & 0,4 & 0 & 0,0 \\
\hline Северо-Кавказский & 0 & 0,0 & 0 & 0,0 & 0 & 0,0 & 0 & 0,0 & 0 & 0,0 \\
\hline Уральский & 31 & 5,1 & 0 & 0,0 & 0 & 0,0 & 2 & 0,1 & 1 & 0,1 \\
\hline Сибирский & 1 & 0,2 & 241 & 23,2 & 1 & 0,1 & 284 & 19,1 & 12 & 1,5 \\
\hline Дальневосточный & 0 & 0,0 & 32 & 3,0 & 2 & 0,2 & 0 & 0,0 & 0 & 0,0 \\
\hline Итог & $\mathbf{6 1 2}$ & $\mathbf{1 0 0 , 0}$ & $\mathbf{1 0 4 1}$ & $\mathbf{1 0 0 , 0}$ & $\mathbf{8 1 6}$ & $\mathbf{1 0 0 , 0}$ & $\mathbf{1 4 8 8}$ & $\mathbf{1 0 0 , 0}$ & $\mathbf{7 7 4}$ & $\mathbf{1 0 0 , 0}$ \\
\hline Неизвестно & $\mathbf{2 6 7}$ & & $\mathbf{2}$ & & $\mathbf{2}$ & & $\mathbf{3}$ & & $\mathbf{8 9}$ & \\
\hline
\end{tabular}

Наибольший объем инвестиций за весь анализируемый период в виде венчурного капитала приходится на Центральный федеральный округ. Более $90 \%$ всех средств в него было вложено в 2014 г. и 2018 г. На втором месте находится Северо-Западный федеральный округ - в 2015 и 2016 гг. на его долю приходится около трети венчурных инвестиций.

Доминирование двух федеральных округов частично объясняется следующим. Организации, занимающиеся разработкой программного обеспечения и интернет-сервисов, оказывающих 
телекоммуникационные услуги и т. д. (как правило, на них приходится большая часть инвестиций), зачастую имеют сеть филиалов, офисов, центров обслуживания в различных регионах нашей страны [7]. Однако при учете инвестиций сделки относились по расположению к головному офису предприятия, получающего инвестиционные ресурсы. Это и привело к тому, что центральный ФО на первом месте по размеру инвестиций, поскольку юридический адрес инновационной организации распложен именно там.

Зачастую единичные, но достаточно крупные сделки вызывали всплеск региональных объемов инвестиций по годам, как это было в Уральском, Сибирском и Северо-Западном ФО.

Результаты. Очевидно, что, для того чтобы увеличить объемы вкладываемых средств в венчурный сектор, повысить эффективность венчурного капитала, необходимо оптимизировать структуру, участников, принципы деятельности инновационного лифта не только на федеральном, но и на региональном уровнях.

Сформулируем принципы работы инновационного лифта на региональном уровне:

- существование всех элементов инновационного лифта и их полноценная работоспособность;

- на каждом этаже инновационного лифта должны работать такие институты поддержки инновационных предприятий, которые им реально необходимы на конкретном этапе развития;

- между всеми участниками инновационного процесса должно быть налажено устойчивое взаимодействие, которое бы давало возможность процессу развития инновационных компаний происходить без остановок [11].

Существующий механизм инновационного лифта необходимо пересматривать. Новую модель инновационного лифта необходимо разрабатывать с учетом «безотходности». Безотходность инновационного лифта означает возможность получения прибыли на любом этапе развития за счет минимизации инвестиционного риска инновационных проектов. Минимизация риска, в частности, будет происходить за счет возможности продажи как самих инвестиционных проектов, так и готового бизнеса за счет выхода инвесторов [1].

Предложенная модель инновационного лифта является своеобразной «венчурной фабрикой», которая представляет собой симбиоз венчурного фонда, бизнес-акселератора и управляющей компании. Работа конкретных специализированных институтов инновационного механизма основана на их сетевом взаимодействии. (табл. 3). Регулирующим органом инновационного лифта на всех этажах является управляющая компания. Последняя выполняет функцию управления на всех стадиях жизненного цикла инновационных проектов за счет участия в деятельности специализированных инфраструктурных институтов.

Рассмотрим, как может быть реализована предложенная модель инновационного лифта на примере конкретного субъекта федерации - Челябинской области.

В роли управляющей компании может выступать АНО Агентство инвестиционного развития Челябинской области. АНО Агентство инвестиционного развития Челябинской области уполномоченная организация правительства региона по работе с инвесторами и сопровождению инвестиционных проектов в режиме «одного окна».

УК должна работать на принципе самоокупаемости: ее расходы должны быть покрыты доходами даже на начальном этапе становления инновационных проектов. Происходить это может за счет реализации результатов анализа трендов экономического и инновационного развития.

Планируется, что доходная часть УК будет складываться за следующих источников:

- доходов от продаж на всех стадиях разработки и реализации проектов;

- вознаграждений от инвесторов корпоративного венчурного фонда;

- вознаграждений от инвесторов корпоративной краудинвестинговой платформы.

На посевном этапе источниками инвестиций должны являться такие институты инфраструктуры венчурного бизнеса, как посевные фонды, корпоративное венчурное инвестирование, бизнес-ангелы и т. д.

Крупнейшими посевными фондами в РФ являются ФРИИ, Altair Capital, Starta Ventures, Phystech Ventures и т. д. [9].

Помимо венчурных фондов источником финансирования инновационных проектов фондов являются так называемые бизнес-ангелы и крупные корпорации, выделяющие часть бюджета на высокорискованные инновационные проекты. 
КУЗНЕЦОВА М.В.

СОВЕРШЕНСТВОВАНИЕ ИННОВАЦИОННОЙ ИНФРАСТРУКТУРЫ НА РЕГИОНАЛЬНОМ УРОВНЕ

Модель регионального инновационного лифта

\begin{tabular}{|c|c|c|c|c|}
\hline \multirow{8}{*}{ 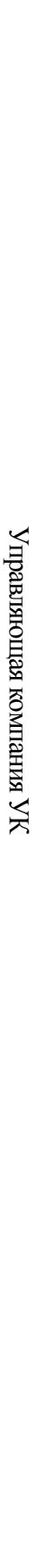 } & \multicolumn{2}{|r|}{ Стадия Институты } & Функции & Результат \\
\hline & \multirow[t]{2}{*}{ 1. Рост } & $\begin{array}{l}\text { Венчурные фонды, } \\
\text { корпоративное } \\
\text { венчурное } \\
\text { инвестирование, } \\
\text { бизнес-ангелы, } \\
\text { коммерческие банки, } \\
\text { корпоративная } \\
\text { краудинвестинговая } \\
\text { платформа }\end{array}$ & $\begin{array}{l}\text { Финансирование: долевое, } \\
\text { заемное }\end{array}$ & \multirow[t]{2}{*}{$\begin{array}{l}\text { 1. Развитие бизнеса. } \\
\text { 2. Продажа готовой продукции. } \\
\text { 3. Продажа бизнеса. }\end{array}$} \\
\hline & & Технопарки, НИИ, ВУЗы & $\begin{array}{l}\text { Предоставление производ- } \\
\text { ственных и офисных поме- } \\
\text { щений, консалтинговых } \\
\text { услуг, экспертиза проектов, } \\
\text { технологический консал- } \\
\text { тинг }\end{array}$ & \\
\hline & \multirow[t]{2}{*}{ 2. Старт } & $\begin{array}{l}\text { Венчурные фонды, } \\
\text { корпоративное } \\
\text { венчурное } \\
\text { инвестирование, } \\
\text { бизнес-ангелы, гранты, корпора- } \\
\text { тивная краудинвестинговая плат- } \\
\text { форма }\end{array}$ & $\begin{array}{l}\text { Финансирование: } \\
\text { долевое, } \\
\text { безвозмездное }\end{array}$ & \multirow[t]{2}{*}{$\begin{array}{l}\text { 1. Формирование бизнес-единиц. } \\
\text { 2. Организация бизнеса. } \\
\text { 3. Продажа проектов. }\end{array}$} \\
\hline & & $\begin{array}{l}\text { НИИ, ВУЗы, бизнес- } \\
\text { инкубаторы }\end{array}$ & $\begin{array}{l}\text { Предоставление } \\
\text { офисных } \\
\text { помещений, консалтинго- } \\
\text { вые услуги, экспертиза про- } \\
\text { ектов, генерирование новых } \\
\text { знаний }\end{array}$ & \\
\hline & \multirow[b]{2}{*}{ Посев } & $\begin{array}{l}\text { Посевные фонды, корпоративное } \\
\text { венчурное инвестирование, биз- } \\
\text { нес-ангелы }\end{array}$ & $\begin{array}{l}\text { Финансирование: } \\
\text { долевое, } \\
\text { безвозмездное }\end{array}$ & \multirow{2}{*}{$\begin{array}{l}\text { 1. Отбор и оформление проек- } \\
\text { тов. } \\
\text { 2. Продажа проектов. }\end{array}$} \\
\hline & & $\begin{array}{l}\text { НИИ, ВУЗы, бизнес- акселерато- } \\
\text { ры }\end{array}$ & $\begin{array}{l}\text { Экспертиза проектов, } \\
\text { предоставление } \\
\text { информационных } \\
\text { услуг, } \\
\text { оборудования }\end{array}$ & \\
\hline & Нулевая & УК & $\begin{array}{l}\text { Анализ динамики } \\
\text { и направлений } \\
\text { возможного } \\
\text { развития } \\
\text { инновационных } \\
\text { идей }\end{array}$ & $\begin{array}{l}\text { 1. Использование результатов } \\
\text { анализа в дальнейшей деятель- } \\
\text { ности. } \\
\text { 2. Продажа результатов анализа } \\
\text { тенденций развития (трендов). }\end{array}$ \\
\hline
\end{tabular}

НИИ, вузы, бизнес-акселераторы призваны обеспечить прочую - нефинансовую составляющую венчурного бизнеса. Главная функция акселератора - сделать запуск новых результативных компаний цикличным, другими словами, поставить на поток производство фирм. В чистом виде бизнес-акселераторы в Челябинской области отсутствуют. В РФ в качестве примера можно привести такие акселераторы, как Акселератор ФРИИ, GenerationS, Global Techinnovations, 2Setup, Бизнес-катализатор и т. д. Что касается научно-исследовательских институтов и институтов как образовательных организаций, то активными участниками венчурного процесса на территории области являются ЮУрГУ, ЧелГУ, МГТУ [8]. С их помощью решается проблема доступа к уникальному научному оборудованию.

На этапе старта к источникам финансирования добавляются венчурные фонды и гранты. В 
Челябинской области в 2008 г. был создан венчурный фонд - Фонд содействия развитию венчурных инвестиций в малые предприятия в научно-технической сфере Челябинской области. Однако каких-либо значительных результатов он не показал.

Особенностью институтов поддержки венчурного бизнеса на этом этапе является наличие бизнес-инкубаторов. Бизнес-инкубатор представляет собой организацию, которая решает задачи, связанные с необходимостью поддержки малых, вновь созданных предприятий и начинающих предпринимателей, которые хотят, но не имеют возможности начать своё дело, с оказанием им помощи в создании жизнеспособных коммерчески выгодных продуктов и эффективных производств на базе их идей. В настоящее время на территории Челябинской области действуют МКУ «Магнитогорский инновационный бизнес-инкубатор», МУ «Озёрский инновационный центр - бизнес-инкубатор», ГБУ Челябинской области «Инновационный бизнесинкубатор».

Фаза роста отличается тем, что у вновь созданных инновационных предприятий появляется возможность привлекать заемный капитал у коммерческих банков. Это обусловлено тем, что венчурный проект уже доказал свою жизнеспособность и с большей долей вероятности будет приносить прибыль. Место бизнес-инкубаторов на этой фазе занимают технопарки.

Выводы. Деятельность всего механизма инновационного лифта должна строиться с учетом следующих принципов:

- привлечение наиболее оптимальных ресурсов с минимумом затрат. Это позволяет с максимальной эффективностью применять интеллектуальные, материальные, трудовые и финансовые ресурсы;

- отслеживание и генерация новых инновационных идей с их последующим развитием;

- УК должна контролировать все стадии реализации инновационных проектов;

- создание непрерывности потока доходов с одновременным избеганием потерь избегание потерь на каждом этапе реализации инновационного проекта;

- переход инновационных проектов от одного этапа реализации при условии целесообразности этого действия;

- сетевой принцип, который подразумевает координацию взаимоувязанных институтов инфраструктуры инновационного предпринимательства;

- прозрачность и гибкость помощи инновационным проектам на каждой стадии развития компании, что способствует привлечению инвесторов.

Литература

1. Богуславский И. В. Механизм венчурного финансирования: модель реализаџии «инноваџионного лифта» [Текст] / И. В. Богуславский, Е.А. Угнич // Фундаментальные исследования. - 2013. - МП. - Ч. 8. C. $1615-1620$.

2. Горский М. Как отремонтировать «инновачионный лифт». М. Горский // Forbes. - 2013. - 27 мая. [Электронный ресурс]. Режим доступа: http://www.forbes.ru/mneniya-column/idei/239647-kakotremontirovat-innovatsionnyi-lift. - (дата обращения: 14.12.2019), свободный. - Загл. с экрана.

3. Гурунян Т. В. Инвестиционно-инновачионный лифт для малого и среднего предпринимательства: вопросы финансирования стартапов / Т. В. Гурунян [Текст] // Вестник Томского государственного университета. Экономика. - 2013. - № 3 (23). - С. 120-126.

4. Дополнительные данные к «Обзору рынка прямых и венчурных инвестиций в России за 2018 год» // Российская ассочиачия венчурного инвестирования (РАВИ). [Электронный ресурс]. Режим доступа: http://www.rvca.ru/upload/files/lib/RVCA-yearbook-2018-Russian-PE-and-VC-market-review-ru-data.xlsx (дата обращения: 05.12.2019), свободный. - Загл. с экрана.

5. Зиновьева Е. Г., Кузнечова М. В. Проблемы венчурного финансирования инновационных проектов в Российской Федераиии // Экономика и менеджмент систем управления. - 2015. - № 2.1. - C. 157-166.

6. Каржаув А. T. Инновационные риски венчурного капитала и управление ими. - М.: ЗАО «Издательство Экономика», 2003. - 512 c.

7. Кузнецова М. В. Пути повышения эффективности венчурного финансирования инновационных проектов: Монография. - М.: ИНФРА-М, Сер. Научная мысль, 2016. - 102 c.

8. Распоряжение от 12.10.2012 года «260-рп Об утверждении стратегии развития инновачионной деятельности в Челябинской области до 2020 года". [Электронный ресурс]. Режим доступа: http:// docs.cntd.ru/document/444933641 (дата обращения: 14.12.2019), свободный. - Загл. с экрана.

9. Рейтинг венчурных фондов - 2017 // Firrma: Медиа-ресурс для технологических предпринимателей, венчурных инвесторов и ГТ-компаний. [Электронный ресурс]. Режим доступа: http://firrma.ru/data/ analytics/93763/?sphrase id=102795 (дата обращения: 15.12.2019), свободный. - Загл. с экрана.

10. Трибушная В. Х. Инновационная инфраструктура как необходимость поддержки наукоемкого предпринимательства: технопарки и стратегическое управление: Монография. Ижевск: Ижевский 
государственный технический университет. - 2011. - 240 с.

11. Угнич Е. А. Развитие малого и среднего предпринимательства в муниципальном образовании: монография / Е. А. Угнич, А. Г. Оганьян. -Ростов-на-Дону: ЮФУ, 2010. - 126 с.

\section{References:}

1. Boguslavskij I. V. Mekhanizm venchurnogo finansirovaniya: model" realizacii «innovacionnogo lifta» [Tekst] / I. V. Boguslavskij, E.A. Ugnich // Fundamental'nye issledovaniya. - 2013. - MP. - CH. 8. - S. $1615-1620$

2. Gorskij M. Kak otremontirovat' «innovacionnyj lift». M. Gorskij // Forbes. - 2013. - 27 maya. [Elektronnyj resurs]. Rezhim dostupa: http://www.forbes.ru/mneniya-column/idei/239647-kak-otremontirovatinnovatsionnyi-lift. - (data obrashcheniya: 14.12.2019), svobodnyj. - Zagl. s ekrana.

3. Gurunyan T. V. Investicionno-innovacionnyj lift dlya malogo i srednego predprinimatel'stva: voprosy finansirovaniya startapov / T. V. Gurunyan [Tekst] // Vestnik Tomskogo gosudarstvennogo universiteta. Ekonomika. - 2013. - № 3 (23). - S. 120-126.

4. Dopolnitel'nye dannye $k$ «Obzoru rynka pryamyh $i$ venchurnyh investicij v Rossii za 2018 god» // Rossijskaya associaciya venchurnogo investirovaniya (RAVI). [Elektronnyj resurs]. Rezhim dostupa: http:// www.rvca.ru/upload/files/lib/RVCA-yearbook-2018-Russian-PE-and-VC-market-review-ru-data.xlsx) (data obrashcheniya: 05.12.2019), svobodnyj. - Zagl. s ekrana.

5. Zinov'eva E. G., Kuznecova M. V. Problemy venchurnogo finansirovaniva innovacionnyh proektov $v$ Rossijskoj Federacii // Ekonomika i menedzhment sistem upravleniya. - 2015. - № 2.1. - S. 157-166.

6. Karzhauv A. T. Innovacionnye riski venchurnogo kapitala $i$ upravlenie imi. - M.: ZAO "Izdatel'stvo Ekonomikall, 2003. - 512 s.

7. Kuznecova M. V. Puti povysheniya effektivnosti venchurnogo finansirovaniya innovacionnyh proektov: Monografiya. - M.: INFRA-M, Ser. Nauchnaya mysl', 2016. - 102 s.

8. Rasporyazhenie ot 12.10 .2012 goda «260-rp Ob utverzhdenii strategii razvitiya innovacionnoj deyatel'nosti $v$ CHelyabinskoj oblasti do 2020 goda». [Elektronnyj resurs]. Rezhim dostupa: http://docs.cntd.ru/ document/444933641 (data obrashcheniya: 14.12.2019), svobodnyj. - Zagl. s ekrana.

9. Rejting venchurnyh fondov - 2017 // Firrma: Media-resurs dlya tekhnologicheskih predprinimatelej, venchurnyh investorov $i$ GT-kompanij. [Elektronnyj resurs]. Rezhim dostupa: http://firrma.ru/data/ analytics/93763/?sphrase_id=102795 (data obrashcheniya: 15.12.2019), svobodnyj. - Zagl. s ekrana.

10. Tribushnaya V. H. Inñovacionnaya infrastruktura kak neobhodimost' podderzhki naukoemkogo predprinimatel'stva: tekhnoparki i strategicheskoe upravlenie: Monografiya. Izhevsk: Izhevskij gosudarstvennyj tekhnicheskij universitet. - 2011. - 240 s.

11. Ugnich E. A. Razvitie malogo i srednego predprinimatel'stva v municipal'nom obrazovanii: monografiya / E. A. Ugnich, A. G. Ogan'yan.-Rostov-na-Donu: YUFU, 2010. - 126 s. 